\title{
Adaptation
}

\section{The Fifteenth Marjory Stephenson Memorial Lecture}

\author{
By PATRICIA H. CLARKE \\ Department of Biochemistry, University College London
}

(Delivered at the General Meeting of the Society for General Microbiology on 6 April 1981)

I would like to thank the President, and Council of the Society, for inviting me to be this year's Marjory Stephenson Memorial Lecturer. It was a great pleasure to me to be asked to give this lecture and I feel honoured that the Society should invite me to do so.

I have noted that in past years some of my distinguished predecessors have started their lectures with a brief account of their own recollections of Marjory Stephenson. I thought I would like to follow their example and, indeed, I can claim to have attended MS's lectures when I was an undergraduate reading Biochemistry. However, I feel a little diffident about telling you this since the experience did not immediately turn me into a microbiologist. On the other hand, although I cannot claim to have been directly influenced by MS in my choice of career, her indirect effect on my future scientific life was quite another matter.

Some years ago Ernest Gale said in the tenth Marjory Stephenson Memorial Lecture that '. . revere her as we may, no one could call her a brilliant lecturer. The lectures might well begin in the middle and end at the beginning but at least we gathered that someone had done something terrific' (Gale, 1971). There are two terrific things that stuck in my mind from MS's lectures. The first was a new and exciting concept, that of 'enzyme adaptation'. I was very interested in enzymes and their activities and I liked the idea that some at least were only present when they were needed. At that time I had no thought of pursuing this any further but the topic of enzyme adaptation was to haunt me for many years and is the main theme of my lecture today.

The second thing was quite different and it was that someone had shown that compounds that were known to be vitamins for man were also growth factors for certain bacteria (Knight, 1937). I was interested in vitamins as well as enzymes and particularly interested in the role of vitamins as coenzymes. This piece of terrific information made me realize for the first time that if you wanted to do fundamental studies in biochemistry you might do well to work with bacteria. The other thought that this information about vitamins and growth factors prompted in my mind was that I would like to work with B. C. J. G. Knight who had made these observations. A few years later I managed to achieve this ambition and I now have great pleasure in thanking Gabe Knight for continuing my education and setting me firmly on the path to becoming a microbiologist.

The adaptive enzyme that had impressed me was formic hydrogenlyase (Fig. 1). Stickland (1929) had shown that washed suspensions of Escherichia coli could convert formate into hydrogen and carbon dioxide, and a few years later Woods (1936) demonstrated that the reaction was reversible. The production of hydrogen by bacteria growing in peptone medium containing fermentable carbohydrates had been known for many years (Pakes \& Jollyman, 1901) and the formic hydrogenlyase reaction is responsible for the gas produced during the fermentation of glucose and other sugars.

Stickland (1929) reported that washed suspensions of $E$. coli grown in tryptic broth did not liberate hydrogen until they had been in contact with formate for $24 \mathrm{~h}$ and thought that the bacteria might well have been growing during this time. However, after hearing about the 


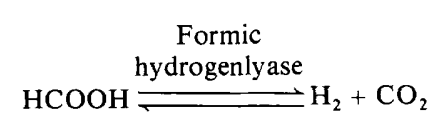

Fig. 1. The formic hydrogenlyase complex is responsible for producing gas from formate as the result of sugar fermentation by enteric bacteria. It was one of the earliest adaptive enzymes to be recognized. (Stephenson \& Stickland, 1932, 1933)

ideas being put forward by Karstrom (1930) on 'constitutive' and 'adaptive' enzymes, Stephenson \& Stickland $(1932,1933)$ decided to reinvestigate the phenomenon. This they proceeded to do in a remarkable series of experiments. In the introduction to the first of their papers they said that 'A provisional theory was put forward suggesting that the production of molecular hydrogen was a function associated with the actual growth of the cells, but the true explanation will be made clear in the course of this paper'. Having made this confident assertion they describe how they first established that formic hydrogenlyase activity was present in washed suspensions of bacteria grown in tryptic broth containing $0.5 \%$ sodium formate but not in bacteria grown in the absence of formate. They also found that cultures grown under strictly anaerobic conditions in broth with formate had more activity than cultures grown in Roux bottles in formate broth exposed to air.

They went on to investigate whether or not the appearance of formic hydrogenlyase activity could be correlated with growth. They established that when $0.5 \%$ formate was added to a culture of $E$. coli, growing in tryptic broth, there was no alteration in the growth rate. Then they measured the rate at which formic hydrogenlyase activity appeared. This was carried out in the following way. A flask containing 31 of tryptic broth was inoculated with $E$. coli and grown for $10 \mathrm{~h}$ at which time the viable count had reached $5 \times 10^{7}$ bacteria $\mathrm{ml}^{-1}$. A sample of $500 \mathrm{ml}$ was removed and immediately a sterile solution of sodium formate was added to the rest of the culture to give a final concentration of $0.5 \%$. Further $500 \mathrm{ml}$ samples were removed at hourly intervals. A small volume of each sample was retained for a viable count and the rest was centrifuged and resuspended in buffer for the formic hydrogenlyase assay. The results showed that there was a dramatic increase in the formic hydrogenlyase activity that reached a maximum within $2 \mathrm{~h}$ without a corresponding increase in cell numbers.

They then examined the time-course of the appearance of formic hydrogenlyase activity on a more modest scale. A washed suspension of $E$. coli was prepared from a culture grown in tryptic broth without added formate. The rate of hydrogen production was measured manometrically. The manometer vessels contained buffer, formate, concentrated tryptic broth and the washed cell suspension and were gassed with nitrogen (Stephenson \& Stickland, 1933). After a lag period of about $1 \mathrm{~h}$ the rate of hydrogen production began to increase. Figure 2 shows the enzyme activity over the experimental period for a 'typical experiment'. They measured the viable count at the start and end of 23 experiments of this sort and found that it did not increase significantly in any of the experiments. It is important to note that the increase in formic hydrogenlyase activity was dependent on the presence of tryptic broth and did not occur if the cells were incubated with formate alone.

From these experiments they concluded that their results were 'sufficient to show that a natural selection plays no part in the formation of the enzyme' and $I$ think this is as far as they got at that time in their search for 'the true explanation'. [It was established later that the formic hydrogenlyase reaction was not due to a single enzyme but to a multienzyme complex (Peck \& Gest, 1957).]

When I first encountered formic hydrogenlyase it was firmly established as an adaptive enzyme and was used as such in the biochemistry practical class, but the experimental system had become rather more streamlined. Figure 3 shows the time-course of such an experiment in which hydrogen production from formate was measured and also hydrogen uptake from a mixture of hydrogen and carbon dioxide. When some years later I adapted this experiment for a practical class in microbial biochemistry at University College London, one of the few 


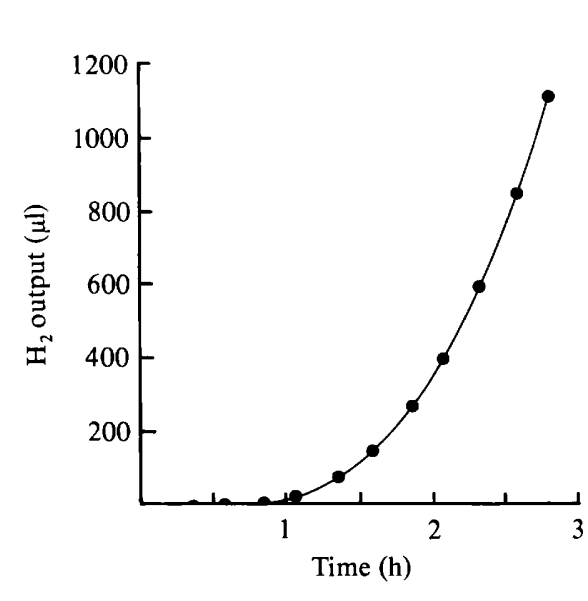

Fig. 2

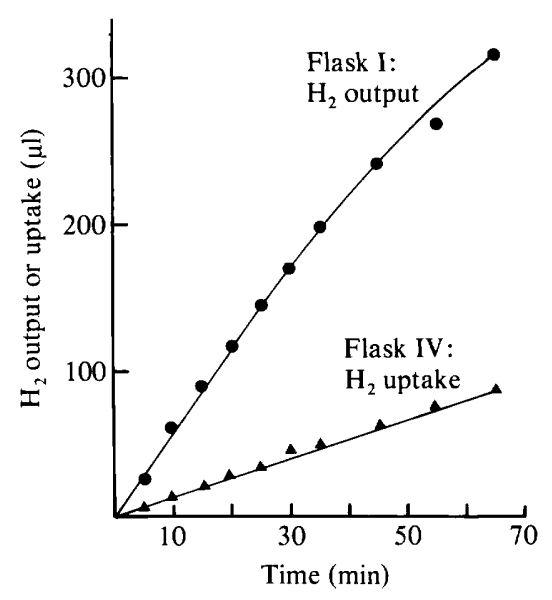

Fig. 3

Fig. 2. Formic hydrogenlyase activity in $E$. coli during adaptation with formate. The bacteria were grown aerobically in the absence of formate and harvested aseptically. A suspension was introduced into a sterile manometer flask containing phosphate buffer, formate and tryptic broth and gassed with $\mathrm{N}_{2}$. After a lag period of $1 \mathrm{~h}$, hydrogen began to be produced. No significant increase in the viable count occurred during the experimental period. (Stephenson \& Stickland, 1933)

Fig. 3. Formic hydrogenlyase activity in washed suspensions of E. coli. Flask I (O) contained $0 \cdot 1 \mathrm{ml}$ suspension of bacteria (grown in tryptic broth containing $0.5 \%$ sodium formate), $100 \mu$ sodium formate, phosphate buffer, $\mathrm{NaOH}$ in the centre well and $\mathrm{N}_{2}$ as the gas phase. Flask IV $(\boldsymbol{\Delta})$ contained a suspension of formate-grown bacteria (but formate as substrate was omitted), bicarbonate buffer, $\mathrm{NaOH}$ in the centre well and $5 \% \mathrm{CO}_{2}$ in $\mathrm{H}_{2}$ as the gas phase. The output of gas from flask $\mathrm{I}$, and the uptake of gas from flask IV, was due to $\mathrm{H}_{2}$ alone. Flask III (not shown) was set up as flask I but with a suspension of bacteria grown aerobically in the absence of formate: no gas production was observed. Flask II (not shown) was set up as flask I but without formate as substrate and with $\mathbf{H}_{2}$ as the gas phase: no gas uptake was observed. (P. H. Clarke \& M. V. Tracey)

modifications I introduced was to add chromotropic acid to the flasks at the end of the experiment. Chromotropic acid gives a violet colour with formate and this reaction was used to demonstrate the presence of formic acid in the flask incubated with hydrogen and carbon dioxide.

The emphasis in these early experiments on whether or not growth occurred during the adaptive production of formic hydrogenlyase seems now somewhat excessive but at the time it was critical to establish this point. These experiments were being carried out long before there were any coherent ideas about bacterial genetics and it was essential to define the problem clearly. In this case the problem was to disentangle temporary and reversible changes in enzyme activities of bacterial populations from those permanent changes due to the selection of new variants. It was not always obvious how to do this and there were many traps for the unwary.

I have referred to 'adaptive enzymes' since this was how formic hydrogenlyase, and other enzymes, were described, but the term 'adaptation' had then, and still has, more than one meaning and this in itself gave rise to some of the confusion in understanding the mechanisms that were involved. Biologists habitually use the term 'adaptation' to describe both the evolutionary changes that allow a species to evolve the characteristics that fit it to a particular ecological niche and also to describe the process whereby individual plants and animals respond to changes in their immediate environment. Stanier (1951) tried to overcome the confusion, between physiological (or phenotypic) changes in bacterial populations and changes due to the selection of mutants, by suggesting that the term 'enzymatic adaptation' should be applied to 'substrate-activated biochemical variations not involving changes in 
genotype'. With this definition we are getting nearer to familiar ways of thinking. The really significant change in terminology came with a review by Monod \& Cohn (1952) which they entitled 'La biosynthèse induite des enzymes (Adaptation enzymatique)'. In the following year the subject of the third symposium of the Society for General Microbiology was 'Adaptation in Micro-organisms' and a new era had begun. Increasingly it was possible to talk about 'induced enzymes' rather than about 'adaptive enzymes' and to argue about possible mechanisms to explain enzyme induction. Monod \& Cohn (1952) pointed out that although in most cases studied so far the substrate of the enzyme had also been the inducer of the enzyme, this was not necessarily true for all systems. They distinguished between the function of the inducer and the function of the substrate. The adaptive enzyme in their studies was the $\beta$-galactosidase of $E$. coli which enables the bacteria to use lactose for growth. They had shown that certain lactose analogues, including various thiogalactosides, could induce $\beta$-galactosidase synthesis even though they were not hydrolysed by the enzyme being induced. These findings paved the way for the study of the kinetics of $\beta$-galactosidase synthesis in exponentially growing cultures with non-substrate inducers. This gratuitous induction, in which the enzyme being studied is totally unnecessary for the growth of the culture, allowed the kinetics of synthesis of a particular enzyme to be dissociated from the overall growth of the culture. It soon became apparent that enzyme induction was not an obscure topic of interest only to microbiologists but a powerful tool for studying de novo protein synthesis.

By the early 1960s, largely as a result of the work carried out in the Institut Pasteur by Jacques Monod and his collaborators, questions about induced enzyme synthesis had almost become synonymous with questions about the synthesis of the $\beta$-galactosidase. The history of much of this elegant work is well-documented in reviews and books (see, for example, Beckwith \& Zipser, 1970; Miller \& Reznikoff, 1978; Lwoff \& Ullman, 1979).

The operon model of Jacob \& Monod (1961) was released at a time when a satisfactory theory for the regulation of enzyme synthesis was badly needed. (In my laboratory we held a three-day discussion to find out if we understood it and to see if it fitted our own data.) The operon model explained with convincing clarity that structural genes for enzymes could be switched off by regulator genes. In the case of $\beta$-galactosidase the lacI gene was said to code for a regulator molecule, called the Lac repressor, which bound to a site called the Lac operator and, as a result, the synthesis of $\beta$-galactosidase and two proteins coded by adjacent genes was blocked. The inducer was thought to bind to the repressor thereby removing it from the operator and allowing the lac structural genes to be expressed. This model has been modified over the last two decades but the essential points remain. This is the classical model for negative control of transcription and it can account for the induction of catabolic enzymes, like $\beta$-galactosidase, and also for the repression of biosynthetic enzymes, such as those for the amino acid tryptophan. For the tryptophan operon it was suggested that the regulator gene, $\operatorname{trp} R$, codes for an inactive apo-repressor that becomes an active repressor when the end-product tryptophan is bound to it. When tryptophan is in excess, the genes for the biosynthesis of tryptophan are switched off. By this time, mutation and selection was no longer a hindrance to the study of events occurring during enzyme induction. On the contrary, it was the development of microbial genetics that led to the elucidation of the operon model. A few years later, the repressor protein coded by the lacI gene was isolated by Gilbert \& Muller-Hill (1966). According to the classical negative control model it was the absence of this regulator gene product in lacI mutants that explained the constitutive synthesis of $\beta$-galactosidase, but it is also possible for mutations in the lacI gene to produce thermolabile repressors that are active only at low temperatures. This was first observed by Horiuchi \& Novick (1961) who isolated mutants that synthesized $\beta$-galactosidase constitutively at $14^{\circ} \mathrm{C}$ after being subjected to heating at $45^{\circ} \mathrm{C}$ for only $15 \mathrm{~min}$ (Fig. 4).

The $\beta$-galactosidase of $E$. coli was not the only adaptive enzyme being studied at that time, and the kinetics of synthesis of some other induced enzymes were more difficult to interpret. 


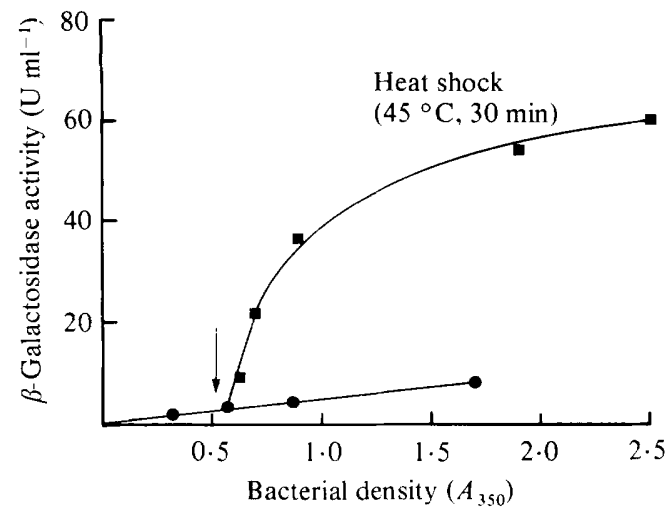

Fig. 4. A thermolabile Lac repressor. The $E$. coli temperature-sensitive constitutive mutant was grown at $14{ }^{\circ} \mathrm{C}(\mathrm{O})$ at which temperature it was inducible for $\beta$-galactosidase synthesis. At the time indicated by the arrow a sample was removed and heated in phosphate buffer at $45^{\circ} \mathrm{C}$ for $30 \mathrm{~min}$. The heated sample was then returned to $14^{\circ} \mathrm{C}$ and growth was allowed to continue ( $\square$ ). $\beta$-Galactosidase was synthesized in the absence of inducer but the rate of synthesis fell off when sufficient repressor had accumulated. (Horiuchi \& Novick, 1961)

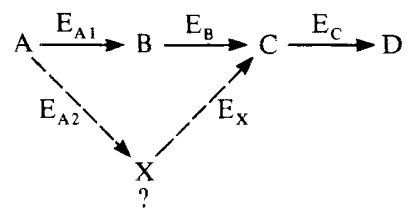

Fig. 5. Simultaneous adaptation or sequential induction. Growth with substrate A results in the adaptive synthesis of the later enzymes of the pathway converting $A$ to $D$. Growth with $B$ or $C$ induces later enzymes but not the preceding enzymes. Stanier (1947) suggested that this technique could be used to elucidate metabolic pathways.

Pollock (1950) had followed the synthesis of penicillinase by Bacillus cereus and found that it differed from $\beta$-galactosidase in that synthesis continued for a long time after the inducer, penicillin, had been removed from the culture medium. Gale (1943) analysed the effects of a variety of different growth conditions on the enzymic content of bacteria. Among these were substrates, compounds other than substrates, temperature, $\mathrm{pH}$ and aeration. Epps \& Gale (1942) found that glucose might affect enzyme production in several different ways. In some cases this could be ascribed to $\mathrm{pH}$ changes resulting from fermentation products, but in other cases the effect appeared to be more closely related to glucose itself.

These were all changes in the phenotypic properties of the culture and Gale (1943) made the important distinction between the potential enzymic constitution of an organism representing its total repertoire (total genetic capacity) and the actual enzymic constitution produced in response to a given set of growth conditions. Some of the responses to the growth environment can be attributed to induction or repression mechanisms but others are more complex and still not fully understood. One of the effects of glucose can now be ascribed to alterations in cyclic AMP levels. Many catabolic operons of E. coli are known to be under positive control by an activator protein that requires cyclic AMP to be effective (Emmer et al., 1970: Zubay et al., 1970). Thus, $\beta$-galactosidase is under negative control by the lacI gene repressor and under positive control by the CRP-cyclic AMP activator protein. Both these control systems act on gene expression at the transcription level.

Stanier (1947) began to look at the regulation of synthesis of some or all of the enzymes of an entire catabolic pathway and described the 'simultaneous adaptation' of successive 
enzymes of a metabolic pathway as a result of the presence of the initial substrate in the growth medium (Stanier, 1951). It is assumed that the enzymes of the hypothetical pathway shown in Fig. 5 are absent unless the compounds A, B etc. are present in the medium. Growth with $A$ induces all the later enzymes, while growth with $B$ induces $E_{B}$ and later enzymes, and growth with $C$ induces $E_{C}$ and later enzymes but not necessarily the earlier enzymes $\mathrm{E}_{\mathrm{A}}$ and $\mathrm{E}_{\mathrm{B}}$. These ideas developed from experiments with cultures of Pseudomonas fluorescens grown on aromatic compounds such as tryptophan and anthranilate. Later it was found that such adaptations did not depend entirely on the successive induction of single enzymes by their substrates but might involve either substrate or product induction of single enzymes or of blocks of enzymes. This process, now known as sequential induction, can be seen as a very efficient and economical way of regulating the synthesis of catabolic enzymes. In this way an organism can grow on intermediates of catabolic pathways without wasting energy on the synthesis of enzymes for preceding steps.

Stanier (1951) suggested that simultaneous adaptation could be used to decide whether or not a particular compound was an intermediate of a pathway. If growth on A induced the synthesis of an enzyme acting on B then it would be reasonable to consider that B was an intermediate of the pathway for the metabolism of A to C. Conversely, if growth on A did not induce enzymes for the metabolism of $\mathrm{X}$ then it might be concluded that $\mathrm{X}$ was not on the pathway for the metabolism of A to C (Fig. 5).

This analysis ran into trouble with terminal respiration in bacteria because of permeability. It seemed obvious that if the tricarboxylic acid (TCA) cycle functioned in terminal respiration of compounds such as acetate and pyruvate, then bacteria grown on these compounds should be able to oxidize any of the cycle intermediates. This proved not to be the case and it was suggested at one time that, because of their lowly position in evolution, bacteria might be restricted to a dicarboxylic acid cycle rather than a tricarboxylic acid cycle. This erroneous view was resolved by identifying and measuring all the TCA cycle enzymes in cell-free extracts (Swim \& Krampitz, 1954) and by experiments on the adaptive synthesis of specific permeases. Kogut \& Podoski (1953) and Barrett \& Kallio (1953) showed that cell-free extracts of $P$. fluorescens oxidized the intermediates of the TCA cycle at a rapid rate whereas there was a lag period before some TCA intermediates were oxidized by whole cells. This was more or less the point at which I started thinking about adaptation again. Pauline Meadow and I examined oxidation rates of whole cells and cell-free extracts of $P$. aeruginos $a$ grown on acetate or pyruvate or intermediates of the TCA cycle. We found that for pyruvate-grown cells there was a short but significant lag before the maximum rate of oxidation of fumarate was reached. The adaptation to fumarate oxidation could be prevented by the addition of chloramphenicol. Bacteria grown on citrate oxidized citrate at a rapid rate, but bacteria grown on other intermediates of the cycle did not do so. Figure 6 shows that extracts of malate-grown bacteria oxidized citrate rapidly, although with whole cells there was a lag of up to $3 \mathrm{~h}$ before a significant rate of oxidation was reached. The inability to oxidize citrate could be ascribed to the absence of an effective citrate uptake system. Figure 7 shows that chloramphenicol prevented the adaptation of fumarate-grown cells to citrate oxidation. In the early stages, when citrate permease activity was negligible, the oxygen uptake was entirely due to endogenous respiration. Later, after almost $3 \mathrm{~h}$, sufficient citrate permease had been synthesized for the uptake of citrate to be no longer rate-limiting. In the presence of only $1 \mu \mathrm{mol}$ fumarate, to provide energy for synthesis, the adaptation lag was reduced to about $1 \mathrm{~h}$, but in both cases chloramphenicol inhibited the adaptive synthesis of the citrate permease (Clarke \& Meadow, 1959).

One of the reasons why Stephenson \& Stickland (1933) had been anxious to establish that formic hydrogenlyase production occurred in the absence of significant growth was that other adaptation experiments were in progress at that time in which growth was essential for adaptation of the bacterial population. These were the experiments on 'training bacteria'. The bacteria were subcultured in media that would encourage them to become resistant to 


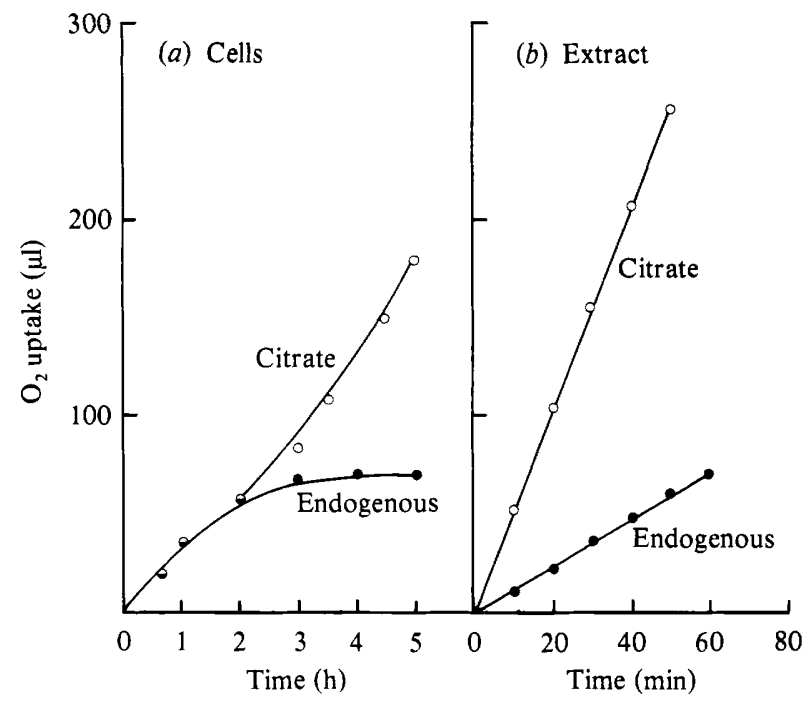

Fig. 6. Oxidative activity of malate-grown $P$. aeruginosa NCTC 8203 . The bacteria were grown aerobically and resuspended in phosphate buffer $(0.05 \mathrm{M}, \mathrm{pH} 7.4)$. Oxygen uptake was measured manometrically with $(a)$ whole cells and $(b)$ cell-free extracts obtained by disruption of the bacteria in a French press. (Clarke \& Meadow, 1959)

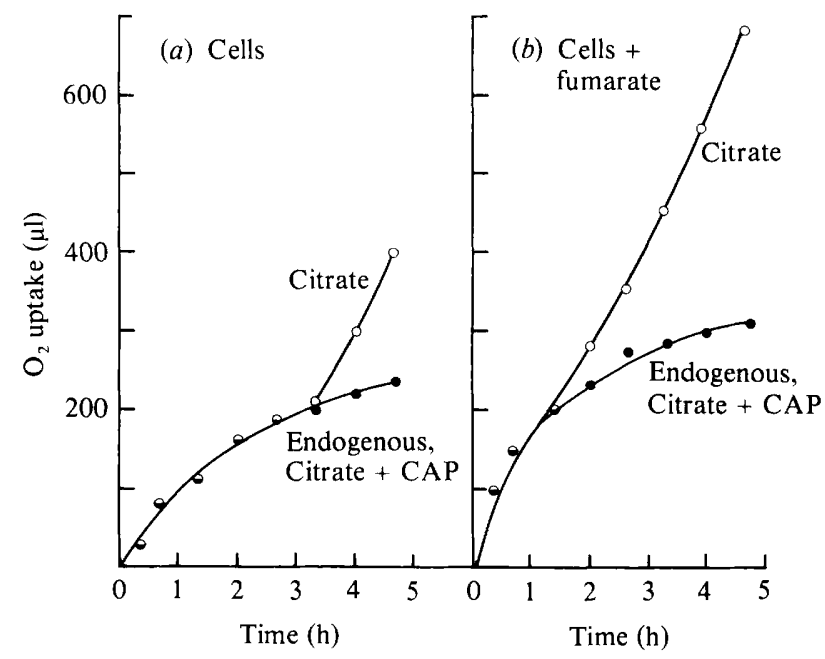

Fig. 7. Oxidative activity of fumarate-grown $P$. aeruginosa NCTC 8203, measured as for Fig. 6 with whole cells. (a) Effect of chloramphenicol (CAP) on adaptation to citrate oxidation. (b) Effect of $1 \mu \mathrm{mol}$ fumarate on reducing the lag for adaptation to citrate. (Clarke \& Meadow, 1959)

increasing amounts of drugs or toxic agents or to dispense with compounds that had been essential for the growth of the original culture. These experiments on 're-educating' bacteria have always seemed to me to have curious moral overtones. It is obvious to those brought up on a diet of microbial genetics, and familiar with the ease with which spontaneous mutants may be selected from bacterial populations, to see that these training experiments were based on mutation and selection. This interpretation did, in fact, soon become clear to all but a few of the experimenters in this field. Those who did not accept this view wrapped up their observations in a dense thicket of mathematics that was impenetrable to all but the most 
intrepid microbiologists. Yet there was much of interest in this work. If we accept that a bacterial species has evolved to fit a particular ecological niche we can ask whether it has lost characteristics that were possessed by its ancestors and, further, whether it is capable of evolution of novel metabolic activities or has reached the end of the road.

One of the training experiments carried out at that time produced a strain of Bact. typhosus (sic) that was able to grow without added tryptophan (Fildes et al., 1933). Many years later a similar experiment was carried out with Lactobacillus casei (Morishita et al., 1974). The wild-type strain required twelve amino acids and four vitamins for growth. The culture was mutagenized and plated on minimal agar containing all the growth requirements except one. By this means mutants were obtained that were able to dispense with one of each of the seven original amino acid requirements. This suggested that single-step mutations were sufficient to restore the biosynthetic pathways for methionine, aspartate, serine, lysine, leucine, isoleucine and tyrosine. Two independent mutations were needed to restore the tryptophan pathway, one allowing the synthesis of anthranilate and the other giving an active tryptophan synthase. Successive single site mutations gave a mutant that had become independent for five amino acids-isoleucine, tyrosine, serine, aspartate and leucine. These results suggested that the genes for the enzymes of the amino acid biosynthetic pathways had been retained by this species and had been inactivated by mutations either in the enzyme structural genes or in the controlling elements. The maximum growth rates of the single-step mutant strains were significantly lower than the wild-type strain in complex media and the strains with more than one new biosynthetic activity grew even more slowly. It appears that $L$. case $i$ has evolved into a nutritionally exacting organism that is well-adapted to its particular ecological niche. The mechanism by which this has been achieved appears to be by inactivating some of its genes rather than by wholesale deletion of the biosynthetic pathways. Since, at least under experimental conditions, some of the $L$. casei biosynthetic pathways can be regained relatively easily, this loss of biosynthetic activity could be also looked upon as an extreme case of regulation of enzyme synthesis involving a reversible genetic mutation.

Catabolic activities may be lost in a similar manner. We have observed that some wild-type strains of $P$. aeruginosa are unable to utilize lysine as a carbon source for growth. A mutation in a regulator gene controlling the synthesis of a lysine permease, and the first enzyme of the lysine decarboxylase pathway, results in a lysine-positive phenotype (Fothergill \& Guest, 1977; Rahman \& Clarke, 1980). Some strains of $P$. aeruginosa are unable to utilize histidine as a carbon source and have a very low rate of histidine uptake. A single mutation affecting a histidine permease allows the inducible histidine catabolic pathway to operate (Potts \& Clarke, 1974). There appears to be no obvious growth advantage in the loss of functional lysine and histidine catabolic pathways and these may be examples of casual inactivation by spontaneous mutation. In each case a functional pathway is regained by a single mutation. However, if a structural gene for an enzyme is not fulfilling its original function then one can ask if it might evolve a new function.

The fermentation of lactose by $E$. coli is normally dependent on the activity of the $\beta$-galactosidase coded by the lac $Z$ gene, but Campbell et al. (1973) reported that a strain of $E$. coli in which the lac operon had been deleted had given rise to mutants with a lactose-positive phenotype. This activity, evolved $\beta$-galactosidase, was due to the $e b g$ genes. This system has been studied in detail by Barry Hall and colleagues who have shown that the wild-type $e b g A^{\circ}$ gene codes for an enzyme with very low $\beta$-galactosidase activity. Mutations in $\operatorname{ebg} A$ produce enzymes with higher affinities and higher maximum rates of lactose hydrolysis. The wild-type strain is inducible for the $e b g A$ enzyme but the maximum induced level is very low and never reaches the threshold in vivo activity required for growth on lactose (Hall \& Clarke, 1977). To gain the lactose-positive phenotype both structural and regulatory gene mutations are needed. Mutations in $e b g A$ produce more active enzymes, and mutations in $e b g R$ give either constitutive mutants or mutants with increased inducibility. 


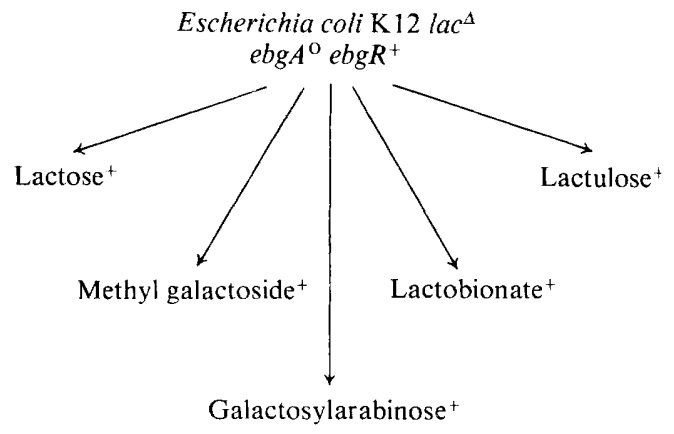

Fig. 8. Evolutionary potential of the Ebg $\beta$-galactosidase of $E$. coli. The wild-type strain lacking the $l a c Z$ gene is unable to grow on lactose or other $\beta$-galactosides. Mutations in $e b g A$ and in $e b g R$ can result in growth on the $\beta$-galactosides shown above. (Hall, 1978)

However, this is not all. Mutations in $e g b A$ can give rise to other novel enzyme activities (Fig. 8) and mutants that grow on lactulose, lactobionate, methyl galactoside or galactosylarabinose (Hall, 1978; Hall \& Zuzel, 1980). The $e b g A^{\circ}$ gene has considerable evolutionary potential although it has no known function in the wild-type strain. It could perhaps be considered as an almost silent or more or less quiescent gene, while the function it might once have fulfilled has been taken over by the lac operon. In this case we can see how mutations in genes that do not appear to be functional in the wild-type strain can allow adaptation to novel growth substrates. These results also show that adaptation based on the acquisition of new enzyme activities may be intimately bound up with the constraints of induction or repression controls. We can ask if similar adaptive changes can be observed with an enzyme that already has an active metabolic role.

Pseudomonas species are able to grow on a wide variety of organic compounds and this catabolic versatility depends on the activities of inducible enzymes. Many of these growth substrates are comparatively recent additions to the biosphere and we can imagine that new enzyme activities might have emerged from old activities by mutational divergence and gene duplications.

We have followed the emergence of new enzyme specificities in an experimental system, starting off with an enzyme of known function, the inducible aliphatic amidase of $P$. aeruginosa. This enzyme allows growth on acetamide and propionamide and these amides are both substrates and inducers. Of the other aliphatic amides, formamide is a poor substrate and a poor inducer, butyramide is not only a very poor substrate but also competes with inducing amides to prevent enzyme synthesis. A small number of substituted amides, such as lactamide ( $\alpha$-hydroxypropionamide) are inducing substrates. The amide growth range of wild-type strains is severely limited by these substrate and inducer specificities. Before we could change this system we needed to understand it and spent some time exploring the biochemistry and genetics of the enzyme and its regulatory system.

The structural gene $a m i E$ is closely linked to the regulator gene $a m i R$ (Fig. 9). We found that mutations in amiR gave constitutive mutants and mutants with altered inducer specificities (Brammar et al., 1967). Some years later we found that some mutations in amiR gave an amidase-negative phenotype, and this was one of the lines of evidence that led us to conclude that amidase synthesis is under positive control by the $a m i R$ protein. It will be remembered that among the lacI mutants were some that were constitutive at higher temperatures because the repressor was thermolabile (Horiuchi \& Novick, 1961). With a positive control system the absence of an effective regulator protein means that the enzyme cannot be synthesized. Some $a m i R$ mutations produce a thermolabile activator protein so 


$$
\mathrm{CH}_{3} \mathrm{CONH}_{2}+\mathrm{H}_{2} \mathrm{O} \stackrel{\begin{array}{c}
P \text { a aeruginosa } \\
\text { amidase }
\end{array}}{\longrightarrow} \mathrm{CH}_{3} \mathrm{COOH}+\mathrm{NH}_{3}
$$

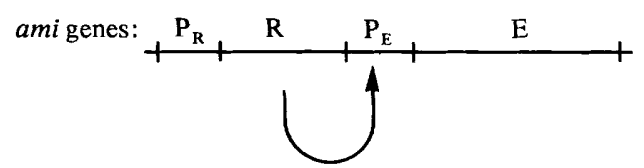

Fig. 9. Amidase genes of $P$. aeruginosa. The inducible amidase of $P$. aeruginosa is under positive control with the amiR gene product activating the transcription of the structural gene amiE. (Farin \& Clarke, 1978)

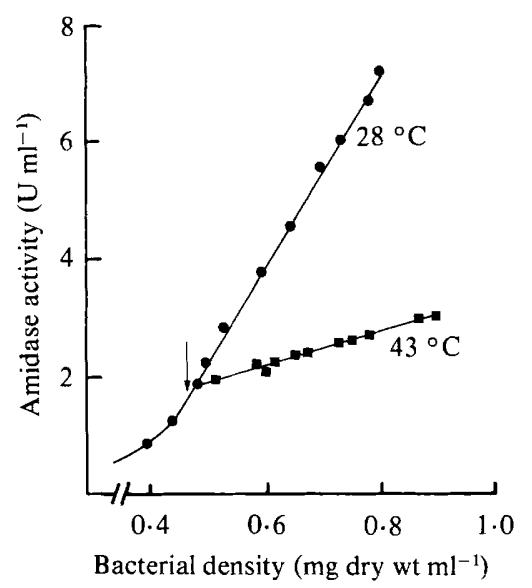

Fig. 10. A thermolabile activator protein. The $P$. aeruginosa temperature-sensitive mutant PAC438 was grown in minimal medium at $28^{\circ} \mathrm{C}(\mathrm{O})$. At the time indicated by the arrow the culture was divided and one part was transferred to $43{ }^{\circ} \mathrm{C}(\square)$. Growth continued but amidase synthesis ceased. (Farin \& Clarke, 1978)

that the mutant is amidase-positive at $28{ }^{\circ} \mathrm{C}$ and amidase-negative at $42{ }^{\circ} \mathrm{C}$. Figure 10 shows that amidase synthesis stopped very soon after the culture was transferred from the permissive to the non-permissive temperature (Farin \& Clarke, 1978). Incidentally, Stickland reported in 1954 that some coliform strains were known to produce acid and gas from glucose at $30^{\circ} \mathrm{C}$, but produced acid without gas at $37^{\circ} \mathrm{C}$ or $44^{\circ} \mathrm{C}$. He showed that this could be correlated with an absence of formic hydrogenlyase (Wolf et al., 1954). It is possible that at least one of the components of the formic hydrogenlyase system is also under positive control.

With $P$. aeruginosa amidase, mutation to constitutivity removes the constraints of inducer specificity and we could then look for mutations in the structural gene giving altered substrate specificities. Figure 11 shows the mutational routes that gave us a series of mutants that grew on amides that could not be metabolized by the wild-type. The first of these was mutant B6 derived from the constitutive mutant $\mathrm{C} 11$. Further mutations gave mutants that grew on valeramide and phenylacetamide. We also asked whether phenylacetamide-utilizing mutants could be isolated via other mutational routes. Figure 11 shows five phenylacetamide-utilizing mutants isolated by independent routes from the wild-type strain. The five phenylacetamidases produced by these mutants differ from one another in substrate specificities, in 


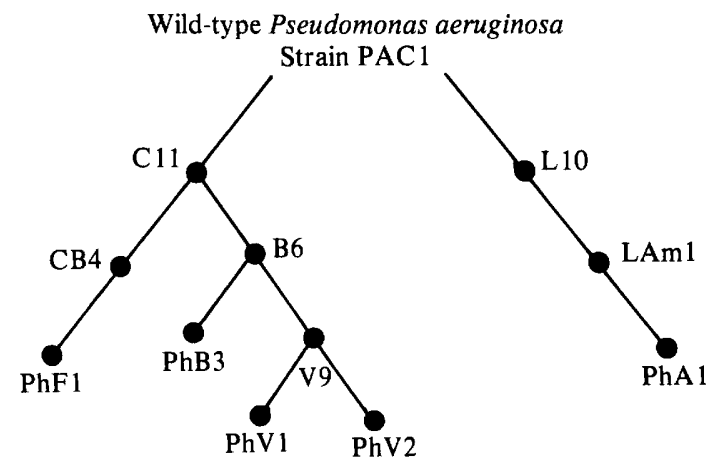

Fig. 11. Evolution of a family of mutant enzymes in $P$. aeruginosa. Wild-type PAC1 grows on acetamide as carbon and nitrogen source. Mutants C11, CB4, L10 are constitutive mutants producing wild-type amidase. Mutants $\mathrm{B} 6, \mathrm{~V} 9, \mathrm{PhF} 1, \mathrm{PhB} 3, \mathrm{PhV} 1, \mathrm{PhV} 2$ and $\mathrm{PhA} 1$ produce amidases with altered substrate specificities that allow growth on butyramide, valeramide and phenylacetamide respectively.

thermal stabilities and in $K_{\mathrm{m}}$ and $V_{\max }$ for their amide substrates (Betz \& Clarke, 1972). All our altered substrate mutants were derived from constitutive strains. Mutant $\mathrm{C} 11$ had given rise to the $\mathrm{B} 6$ family of mutants including mutants $\mathrm{PhB3}, \mathrm{PhV} 1$ and $\mathrm{PhV} 2$, producing thermostable phenylacetamidases. Another constitutive mutant CB4 gave rise by a single mutation to mutant $\mathrm{PhF} 1$ producing a thermolabile phenylacetamidase. Strain L10 is both constitutive and resistant to catabolite repression and gave rise, via an amidase-negative mutant LAm1, to mutant PhA1 producing a very unstable enzyme. The alterations in substrate specificities could be attributed to a succession of single-site mutations in the structural gene for the enzyme.

Mutation amiE16 in strain B6 is retained during the subsequent evolutionary events in the B6 mutant family and is a substitution of phenylalanine for serine at position 7 from the $N$-terminus (Paterson \& Clarke, 1979). DNA sequencing confirms this and shows that the codon change must be from serine, UCC, to phenylalanine, UUC (W. J. Brammar, personal communication).

The wild-type amidase is an inducible enzyme and we felt that the cycle of evolution of new catabolic activity should be completed by a change in inducer specificity corresponding to the change in substrate specificity. We chose to look for a butyramide-inducible mutant producing B amidase. We could not select this mutant directly from strain B6 but did so in an indirect manner. Mutant PhB3 carries mutations amiR11 and amiE16,67 and is constitutive for the $\mathrm{PhB} 3$ phenylacetamidase which has lost activity for acetamide. Mutant PhB3 was crossed with the acetamide-negative mutant Am7 carrying amiR ${ }^{+}$amiE7. Among the recombinants were some that were wild-type inducible but produced the altered $B$ amidase $\left(a m i R^{+}\right.$amiE 16). These strains could not grow on butyramide since butyramide did not induce enzyme synthesis. Attempts were made on a number of separate occasions to isolate butyramide-inducible strains from these recombinants, but the butyramide-positive mutants isolated usually turned out to be constitutive. Recently, with the assistance of some of our final year students, we isolated PAC181 (amiR206 amiE16), a butyramide-inducible strain producing B amidase. With this mutant we have now completed the cycle and obtained a strain of $P$. aeruginosa in which a newly-evolved enzyme can be induced by its novel substrate (Turberville \& Clarke, 1981).

It is, however, quite common for a new growth phenotype to result from a regulatory mutation alone. Mutants able to grow on unnatural pentoses and pentitols are of frequent occurrence and this can often be ascribed to a mutation leading to constitutive synthesis of an 
existing enzyme with low activity towards the novel substrate. For example, wild-type Klebsiella aerogenes grows on ribitol and D-arabitol but not on xylitol. Mutants growing on xylitol were found to be constitutive for ribitol dehydrogenase (Mortlock et al., 1965). One of the constitutive mutants of $K$. aerogenes 1033 gave rise to a faster-growing strain which produced a constitutive ribitol dehydrogenase with a higher affinity for xylitol (Wu et al., 1968). Thus, regulatory mutations that open out the possibilities for later mutations in structural genes may be of general importance in evolutionary adaptation.

The new growth phenotypes based on the Ebg enzymes of $E$. coli and amidases of $P$. aeruginosa depended on single-site mutations in structural genes and appropriate mutations in regulator genes. However, this is not the only way to gain new metabolic activities. About 20 years ago it began to look as if mutation and selection could not account for the rapid spread of antibiotic resistance through bacterial populations. It was found that among the enteric bacteria some genes coding for resistance to antibiotics were not located on the chromosome but were carried on transmissible extrachromosomal elements or plasmids. This is a very rapid way of gaining drug resistance. Watanabe \& Fukasawa (1961) found that multiple resistance for streptomycin, chloramphenicol, tetracycline and sulphonamide was transferred from a resistant to a sensitive strain in about $15 \mathrm{~min}$. The resistance characters were expressed in the recipient before the first cell division and were stable in subsequent generations. This was, indeed, an example of the inheritance of acquired characters although not in the original Lamarckian sense.

Within a few years it was discovered that genes for catabolic enzymes might also be carried on plasmids, and this first became apparent from the discovery that certain catabolic activities could be lost and regained. Catabolic plasmids are frequently found in Pseudomonas spp. and account in part for the catabolic versatility of this group. Among the catabolic plasmids that can be readily transferred by conjugation between $P$. putida and $P$. aeruginos $a$ are CAM (camphor utilization), TOL (toluene, $m$-xylene, $p$-xylene utilization) and NAH (naphthalene utilization) (Rheinwald et al., 1973; Williams \& Murray, 1974; Dunn \& Gunsalus, 1973). The catabolic plasmids may carry genes for entire degradative pathways. The TOL and NAH plasmids carry not only the genes for the initial attack on these compounds but also the set of genes for all the enzymes of the meta-cleavage pathway for aromatic compounds.

The discovery that catabolic genes may be carried on plasmids immediately raises the question of transfer of genes between chromosomes and plasmids. This occurs very readily for some drug resistance genes. We know that the $\beta$-lactamase gene, conferring resistance to penicillin, may be within a mobile genetic element called a transposon that can move from plasmid to chromosome and plasmid to plasmid (Bukhari et al., 1977). Many mobile genetic elements are now known and these entities offer a new range of evolutionary possibilities (see Cold Spring Harbor Symposia on Quantitative Biology, 1981, 45, on movable genetic elements). Catabolic genes may also be contained within transposable elements. Cornelis et al. (1978) reported that transposon Tn951, originally identified on a plasmid from Yersinia enterocolitica, carried an active lactose operon. The transposon contained lacIZ $Y$ genes that were homologous with those of the lac operon of $E$. coli. Further, the Tn951 lac genes could be transferred in vivo to the drug resistance plasmid RP1 which has a very wide host-range.

The total bacterial genome must now be considered to comprise many different genetic elements. The chromosome contributes the major gene complement but a bacterium may contain a number of additional genetic elements (see Bukhari et al., 1977). These may include autonomous genetic elements, plasmids and prophages, which are replicons in their own right. In addition are the transposons which can transfer from one replicon to another but are incapable of independent existence. An even smaller class of genetic element is that known as the insertion sequence or IS element. The first indication of IS elements came from the observation that mutations in the gal operon could be caused by the insertion of additional 
sequences of DNA (Shapiro, 1969). It is now known that copies of several different IS elements occur on both chromosomes and plasmids and may account for recombination between them. Insertion of a transposon or IS element within a gene results in mutation, but perhaps more significant for the evolution of new activities is that genetic rearrangements may be produced by deletion or duplication of adjacent DNA. Deletion of DNA sequences may fuse structural genes together or bring them under the control of other promoters and operators. If structural genes are fused to new control regions the regulation of synthesis of the enzymes coded by those genes will be altered.

Duplication of genes, together with mutational divergence, can provide a mechanism for increasing the metabolic potential of an organism. Evidence for past duplication comes from sequence similarities of enzymes with related functions, but duplications have also been observed in experimental systems. Novick \& Horiuchi (1961) selected strains that were hyper-producers of $\beta$-galactosidase by growing $E$. coli in a chemostat with limiting lactose and they showed that the hyper-production could be ascribed to duplication of the chromosomal lac $Z$ gene. Chemostat growth on xylitol of ribitol dehydrogenase-constitutive mutants of $K$. aerogenes produces strains that are hyper-producers of ribitol dehydrogenase which has low activity towards xylitol (Mortlock \& Wood, 1971; Rigby et al., 1974). Inderlied \& Mortlock (1977) found that the gene duplication was limited to the ribitol dehydrogenase gene and that there was no duplication of the closely linked structural genes. Neuberger \& Hartley (1981) found that one of their hyper-producing strains had acquired an additional $5.8 \mathrm{~kb}$ segment that contained the linked genes for ribitol dehydrogenase and D-arabitol dehydrogenase. The general similarities and the close linkage of the ribitol and D-arabitol operons had previously led Charnetsky \& Mortlock (1974) to suggest that they might have evolved by duplication and modification of common ancestral genes. The experimental systems in which duplication of pentitol genes occurred may be analogous to the natural evolution of these operons.

The transfer of chromosomal genes to plasmids can give another type of gene duplication, and if the plasmids are transmissible this would allow genes to move into another bacterial host which might be the same species, or in some cases an unrelated species. The sex factor of $E$. coli can exist either as an autonomous plasmid or integrated into the chromosome. The $\mathrm{F}$ factor can be excised from the chromosome but, occasionally, some chromosomal genes may also be excised to form F-prime plasmids such as F'lac. The F-prime plasmids can be introduced into recipients carrying identical, or non-identical, copies of lac genes on the chromosome. Experiments with F'lac plasmids were important in establishing that the wildtype inducible $\mathrm{lacI}^{+}$gene was trans-dominant to a constitutive lacI gene and provided evidence for negative control by the lac repressor (Jacob \& Monod, 1961).

We had been considering that the next stage in the evolution of the amidase of $P$. aeruginosa might be to move it around a bit. Bruce Holloway, who has pioneered Pseudomonas genetics, found that the broad host-range plasmid R68 (=RP1) could act as a sex factor in some $P$. aeruginosa strains and promote transfer of chromosomal genes. $\mathrm{He}$ selected for enhanced chromosome-mobilizing activity and obtained the derivative R68.45 which is also capable of incorporating sequences of chromosomal DNA to form R-primes (Haas \& Holloway, 1976: Holloway, 1978). The special properties of R68.45 appear to be due to a short duplication which has generated a highly transposable insertion sequence designated IS21 (Reiss et al., 1980; Willetts et al., 1981). The R-prime plasmid pMO780, which carries genes $\arg F$ and $\arg G$ and also wild-type $a m i$ genes, was isolated by $\mathrm{A}$. D. Morgan (personal communication).

Plasmid pMO780 is about twice the size of R68.45 and the chromosomal insert is about $50 \mathrm{~kb}$ (C. M. Rice, personal communication). We find that the ami genes from $P$. aeruginosa (strain PAO) can be expressed in E. coli, but not very well. Plasmid pMO780 was transferred into $E$. coli 4100 ( $\operatorname{argF} \operatorname{argI})$ by selecting for arginine prototrophy and resistance to 
carbenicillin and kanamycin. These strains grew slowly on minimal plates containing glucose as carbon source and acetamide as nitrogen source. Faster-growing strains were selected by repeated subculture in liquid medium or as larger colonies on plates. The ami genes are now in a new environment and there are several ways in which expression might be increased. Mutations in $E$. coli genes could alter the RNA polymerase, or the catabolic gene activator protein, to improve interactions with the amidase promoter. Mutations in the amidase promoter or in the amiR gene could also lead to improvements in the rate of amidase synthesis. We have examined only a few of these faster-growing strains so far. One of them is constitutive, and this suggests that in this case the mutation might be in the amidase regulator gene, amiR. We intend to continue to follow the adaptation of the amidase genes of $P$. aeruginosa to their new environment in $E$. coli, a bacterium that differs in many respects from the original host species.

In this lecture I have retraced paths followed by some of the pioneering explorers of the mechanisms whereby bacteria adapt to new environments. We no longer make the simple distinction between 'adaptive enzyme synthesis' and 'natural selection' but see a complexity of processes that we can explore at the molecular level.

In this lecture I have taken as my definition of adaptation one much older than any of those used in the work I have discussed. It was first used in 1790 (see Shorter Oxford English Dictionary) and is 'the process of modifying so as to suit new conditions'. It gives plenty of scope to consider all the experimental evidence in the light of the new contributions from molecular biology. I have endeavoured, in the spirit of Marjory Stephenson, to give a 'true explanation' of the phenomena I have described but I am aware of how much we still do not know. So I must conclude by saying that although I hope I have presented the truth, and nothing but the truth, the 'whole truth' is yet to come.

\section{REFERENCES}

Barrett, J. T. \& Kallio, R. E. (1953). Terminal respiration in Pseudomonas fluorescens. Component enzymes of the tricarboxylic acid cycle. Journal of Bacteriology 66, 517-525.

BECKWITH, J. R. \& ZIPSER, D. (1970). The Lactose Operon. New York: Cold Spring Harbor Laboratory.

Betz, J. L. \& Clarke, P. H. (1972). Selective evolution of phenylacetamide-utilizing strains of Pseudomonas aeruginosa. Journal of General Microbiology 73, 161-174.

Brammar, W. J., Clarke, P. H. \& Skinner, A. J. (1967). Biochemical and genetic studies with regulator mutants of the Pseudomonas aeruginosa 8602 amidase system. Journal of General Microbiology 47, 87-102.

BUkHARI, A. I., Shapiro, J. A. \& ADHYA, S. L. (1977). DNA Insertion Elements, Plasmids and Episomes. New York: Cold Spring Harbor Laboratory.

Camprell, J. H., Lengyel, J. A. \& Langridge, J. (1973). Evolution of a second gene for $\beta$ galactosidase in Escherichia coli. Proceedings of the National Academy of Sciences of the United States of America 70, 1841-1845.

Charnetsky, W. T. \& Mortlock, R. P. (1974). Close genetic linkage of the determinants of the ribitol and $\mathrm{D}$-arabitol catabolic pathways in
Klebsiella aerogenes. Journal of Bacteriology 119, 176-182.

Clarke, P. H. \& Meadow, P. M. (1959). Evidence for the occurrence of permeases for tricarboxylic cycle intermediates in Pseudomonas aeruginosa. Journal of General Microbiology 20, 144-155.

Cornelis, G., Ghosal, D. \& Saedler, H. (1978). Tn 951: a new transposon carrying a lactose operon. Molecular and General Genetics 160, 215-224.

Dunn, N. W. \& Gunsalus, I. C. (1973). Trans missible plasmid coding early enzymes of naphthalene oxidation in Pseudomonas putida. Journal of Bacteriology 114, 974-979.

Emmer, M., De Crombrugghe, B., Pastan, I. \& Perlman, R. (1970). Cyclic AMP receptor protein of $E$. coli: its role in the synthesis of inducible enzymes. Proceedings of the National Academy of Sciences of the United States of America $\mathbf{6 6}$, 480-487.

EPPS, H. M. R. \& GALE, E. F. (1942). The influence of the presence of glucose during growth on the enzymic activities of Escherichia coli: comparison of the effect with that produced by fermentation acids. Biochemical Journal 36, 619-623.

Farin, F. \& Clarke, P. H. (1978). Positive regulation of amidase synthesis. Journal of Bacteriology 135, 379-392.

Fildes, P., Gladstone, G. P. \& Knight, B. C. J. G. 
(1933). The nitrogen and vitamin requirements of $B$. typhosus. British Journal of Experimental Pathology 14, 189-196.

Fothergill, J. C. \& Guest, J. R. (1977). Catabolism of L-lysine by Pseudomonas aeruginosa. Journal of General Microbiology 99, 139-155.

Gale, E. F. (1943). Factors influencing the enzymic activities of bacteria. Bacteriological Reviews 7, 139-173.

GAle, E. F. (1971). 'Don't talk to me about permeability'. Journal of General Microbiology 68, $1-14$.

Gilbert, W. \& MUller-Hill, B. (1966). Isolation of the Lac repressor. Proceedings of the National Academy of Sciences of the United States of America 56, 1891-1898.

HAAS, D. \& Holloway, B. W. (1976). R factor with enhanced sex factor activity in Pseudomonas aeruginosa. Molecular and General Genetics 144, 243-251.

HALL, B. G. (1978). Experimental evolution of a new enzymatic function. II, Evolution of multiple functions for ebg enzyme in $E$. coli. Genetics 89, 453-465.

Hall, B. G. \& Clarke, N. D. (1977). Regulation of newly evolved enzymes. III, Evolution of the ebg repressor during selection for enhanced lactase activity. Genetics 85, 193-201.

HALl, B. G. \& ZuZel, T. (1980). Evolution of new enzymatic function by recombination within a gene. Proceedings of the National Academy of Sciences of the United States of America 77, 3529-3533.

HollowAY, B. W. (1978). Isolation and characterization of an $\mathrm{R}^{\prime}$ plasmid in Pseudomonas aeruginosa. Journal of Bacteriology 133, 1078-1082.

HoriuchI, T. \& Novick, A. (1961). A thermolabile repression system. Cold Spring Harbor Symposia on Quantitative Biology 26, 247-248.

INDERLIED, C. B. \& MoRTLOCK, R. P. (1977). Growth of Klebsiella aerogenes on xylitol: implications for bacterial enzyme evolution. Journal of Molecular Evolution 9, 181-190.

JACOB, F. \& MONOD, J. (1961). Genetic regulatory mechanisms in the synthesis of proteins. Journal of Molecular Biology 3, 318-356.

KaRSTrom, H. (1930). Über die Enzymbildung in Bakterien. Thesis, Helsingfors, Finland.

KNIGHT, B. C. J. G. (1937). The nutrition of Staphylococcus aureus; nicotinic acid and vitamin B1. Biochemical Journal 31, 731-787.

Kogut, M. \& Podoski, E. P. (1953). Oxidative pathways in a fluorescent Pseudomonas. Biochemical Journal 55, 800-811.

LwoFf, A. \& Ullman, A. (editors) (1979). Origins of Molecular Biology. A Tribute to Jacques Monod. New York: Academic Press.

Miller, J. H. \& RezNikoff, W. S. (editors) (1978). The Operon. New York: Cold Spring Harbor Laboratory.

MonoD, J. \& CoHN, M. (1952). La biosynthèse induite des enzymes (Adaptation enzymatique). Advances in Enzymology 13, 67-119.

Morishita, T., Fukada, T., Shirota, M. \& Yura, T. (1974). Genetic basis of nutritional requirements in Lactobacillus casei. Journal of Bacteriology $\mathbf{1 2 0}$, 1078-1084.
Mortlock, R. P. \& Wood, W. A. (1971). Genetic and enzymatic mechanisms for the accommodation to novel substrates by Aerobacter aerogenes. In Biochemical Responses to Environmental Stress, pp. 1-14. Edited by I. A. Bernstein. London: Plenum Press.

Mortlock, R. P., Fossitt, D. D. \& Wood, W. A. (1965). A basis for utilization of unnatural pentoses and pentitols by Aerobacter aerogenes. Proceedings of the National Academy of Sciences of the United States of America 54, 572-579.

Neuberger, M. S. \& HaRTley, B. S. (1981). Structure of an experimentally evolved gene duplication encoding ribitol dehydrogenase in a mutant of Klebsiella aerogenes. Journal of General Microbiology 122, 181-191.

Novick, A. \& Horiuchi, T. (1961). Hyper-production of $\beta$-galactosidase by Escherichia coli bacteria. Cold Spring Harbor Symposia on Quantitative Biology 26, 239-245.

Pakes, W. C. C. \& Jollyman, W. H. (1901). The bacterial decomposition of formic acid into carbon dioxide and hydrogen. Journal of the Chemical Society 79, 386-391.

Paterson, A. \& Clarke, P. H. (1979). Molecular basis of altered enzyme specificities in a family of mutant amidases from Pseudomonas aeruginosa. Journal of General Microbiology 114, 75-85.

PeCK, H. D. \& Gest, H. (1957). Formic dehydrogenase and the hydrogen-lyase enzyme complex in coli-aerogenes bacteria. Journal of Bacteriology 73, 706-721.

Pollock, M. (1950). Penicillinase adaptation in $B$. cereus: adaptive enzyme formation in the absence of free substrate. British Journal of Experimental Pathology 31, 739-753.

Potts, J. R. \& Clarke, P. H. (1974). The regulation of histidine catabolism in Pseudomonas aeruginosa. Proceedings of the Society for General Microbiology 1, 63 .

Rahman, M. \& Clarke, P. H. (1980). Genes and enzymes of lysine catabolism in Pseudomonas aeruginosa. Journal of General Microbiology 116, 357-369.

Reiss, G., Holloway, B. W. \& Puhler, A. (1980). R68.45, a plasmid with chromosome mobilizing ability (Cma) carries a tandem duplication. Genetical Research 36, 99-109.

Rheinwald, J. G., Chakrabarty, A. M. \& Gunsalus, I. C. (1973). A transmissible plasmid controlling camphor oxidation in Pseudomonas putida. Proceedings of the National Academy of Sciences of the United States of America 70, 885-887.

Rigby, P. W. J., Burleigh, B. D. \& Hartley, B. S. (1974). Gene duplication in experimental enzyme evolution. Nature, London 251, 200-204.

Shapiro, J. A. (1969). Mutations caused by the insertion of genetic material into the galactose operon of Escherichia coli. Journal of Molecular Biology 40, 93-105.

STANIER, R. Y. (1947). Simultaneous adaptation: a new technique for the study of metabolic pathways. Journal of Bacteriology 54, 339-357.

STANIER, R. Y. (1951). Enzymatic adaptation in bacteria. Annual Review of Microbiology 5, 35-56. 
Stephenson, M. \& Stickland, L. H. (1932). Hydrogenlyases. Bacterial enzymes liberating molecular hydrogen. Biochemical Journal 26, 712724.

Stephenson, M. \& Stickland, L. H. (1933). Hydrogenlyases. Further experiments on the formation of formic hydrogenlyase by Bact. coli. Biochemical Journal 27, 1528-1532.

STICKLAND, L. H. (1929). The bacterial decomposition of formic acid. Biochemical Journal 23, 1187-1198.

Swim, H. E. \& Krampitz, L. O. (1954). Acetic acid oxidation by Escherichia coli: evidence for the occurrence of a tricarboxylic acid cycle. Journal of Bacteriology 67, 419-425.

Turberville, C. \& Clarke, P. H. (1981). A mutant of Pseudomonas aeruginosa PAC with an altered amidase inducible by the novel substrate. FEMS Microbiology Letters 10, 87-90.

Watanabe, T. \& Fukasawa, T. (1961). Episome mediated transfer of drug resistance in Enterobacteriaceae. 1. Transfer of resistance factors by conjugation. Journal of Bacteriology 81, 667-678.

Willetts, N. S., Crowther, C. \& Holloway, B. W. (1981). IS21 and chromosome mobilization by
R68.45. Society for General Microbiology Quarterly $8,88$.

Williams, P. A. \& Murray, K. (1974). Metabolism of benzoate and the methylbenzoates by Pseudomonas putida (arvilla) mt-2. Evidence for the existence of a TOL plasmid. Journal of Bacteriology 120, 416-423.

Wolf, J., Stickland, L. H. \& Gordon, J. (1954). Enzymes concerned with gas formation by some coliform bacteria. Journal of General Microbiology 11, 17-26.

Woods, D. D. (1936). Hydrogenlyases IV. The synthesis of formic acid by bacteria. Biochemical Journal 30, 515-527.

Wu, T. T., Lin, E. C. C. \& Tanaka, S. (1968). Mutants of Aerobacter aerogenes capable of utilizing xylitol as a novel carbon source. Journal of Bacteriology 96, 447-456.

Zubay. G., Schwartz, D. \& Beckwith, J. (1970). Mechanism of activation of catabolite-sensitive genes: a positive control system. Proceedings of the National Academy of Sciences of the United States of America 66, 104-1 10. 